\title{
Silica dust, radon and death from non-malignant respiratory diseases in German uranium miners
}

\author{
M Kreuzer, ${ }^{1}$ M Sogl, ${ }_{1}^{1}$ I Brüske, ${ }^{2}$ M Möhner, ${ }^{3}$ D Nowak, ${ }^{4}$ M Schnelzer, ${ }^{1}$ L Walsh ${ }^{1}$
}

${ }^{1}$ Department of Radiation Protection and Health, Federal Office for Radiation Protection, Neuherberg, Germany ${ }^{2}$ Department Epidemiology I, Helmholtzzentrum München Neuherberg, Germany ${ }^{3}$ Department of 'Work and Health', BAUA, Federal Institute for Occupational Safety and Health, Berlin, Germany

${ }^{4}$ Institut for Occupational Medicine and Environmental Medicine, LMU München, Munich, Germany; Member of the German Center for Lung Research (DZL)

Correspondence to Dr Michaela Kreuzer, Department of Radiation Protection and Health, Federal Office for Radiation Protection Ingolstaedter Landstr. 1, Neuherberg 85764, Germany; mkreuzer@bfs.de

Received 30 April 2013 Revised 13 August 2013

Accepted 23 September 2013 Published Online First

14 October 2013

\begin{tabular}{l}
\hline To cite: Kreuzer M, Sogl M, \\
Brüske I, et al. Occup \\
Environ Med 2013;70:869- \\
875. \\
\hline
\end{tabular}

\section{ABSTRACT}

Objective To quantify the relationship between death from non-malignant respiratory diseases (NMRD) and exposure to silica dust or radon in a cohort of 58690 former German uranium miners.

Methods In the follow-up period from 1946 to 2008, a total of 2336 underlying deaths from NMRDs occurred, including 715 deaths from chronic obstructive pulmonary diseases (COPD) and 975 deaths from silicosis or other pneumoconiosis. Exposure to respirable crystalline silica and radon was individually assessed by means of a comprehensive job-exposure matrix. Risk analyses were based on a linear Poisson regression model with the baseline stratified by age, calendar year and duration of employment.

Results There was no increase in risk of death from COPDs or any other NMRDs in relation to cumulative exposure to silica (mean $=5.9, \mathrm{max}=56 \mathrm{mg} / \mathrm{m}^{3}$-years), except in the group of deaths from silicosis or other pneumoconiosis. Here, a strong non-linear increase in risk was observed. Cumulative radon exposure (mean=280; $\max =3224$ Working Level Months) was not related to death from COPDs or any other NMRDs.

Conclusions The present findings do not indicate a relationship between mortality from COPD with silica dust or radon. However, validity of cause of death and lack of control for smoking remain potential sources of bias.

\section{INTRODUCTION}

There is evidence from epidemiological and pathological studies that exposure to respirable silica dust causes silicosis, lung cancer and chronic obstructive pulmonary diseases (COPD). ${ }^{1}$ COPD is one of the main causes of morbidity and mortality worldwide. ${ }^{2}$ It is associated with a progressive, largely irreversible loss of lung function and can ultimately be fatal. ${ }^{2}$ The relationship of COPD morbidity and silica dust exposure has been quantified. ${ }^{4-6}$ However, evidence relating to silica-induced COPD mortality is inconclusive and studies are rare. ${ }^{7-13}$ Silicosis is an acknowledged occupational disease caused by silica dust. Death from silicosis-as the most severe outcome-is rarely investigated due to small numbers of deaths. Mortality studies consistently confirm an increase in risk with increasing silica dust exposure, ${ }^{7} 811$ 13-16 even below occupational exposure limits. ${ }^{7} 1415$

Residential radon exposure has recently been suggested as possibly associated with death from COPDs in the prospective American Society Cancer Prevention Study II (CPS-II). ${ }^{17}$ In the CPS-II study, ${ }^{17}$ a statistically significant positive

\section{What this paper adds}

- Radon and crystalline silica exposure are known lung carcinogens, but few studies investigated their relationship with mortality from non-malignant respiratory diseases.

- The present cohort study indicated no relationship between silica dust and death from non-malignant respiratory diseases, even at high exposure levels.

- A strong non-linear relationship between silicosis mortality and cumulative silica exposure was confirmed here.

- No association was found between mortality from chronic obstructive pulmonary disease (COPD) and radon, in contrast with the results reported in a recently published large ecological study.

exposure-response relationship between mean county-level of radon concentrations and mortality from COPDs (13 541 deaths) was found. The study was a partially ecological study with individual data on deaths from COPDs and potential confounders such as smoking, but regionally aggregated data on residential radon. ${ }^{17}{ }^{18}$ Bias through misclassification of exposure is therefore of concern. There are few other epidemiological studies that examined mortality from COPDs in relation to radon exposure. An excess compared with national rates was observed among white miners in the Colorado Plateau uranium miner study ( $\mathrm{n}=197$ deaths), ${ }^{19}$ which was attributed to smoking pattern. No relationship with cumulative radon exposure was found either in the French uranium miner cohort with respect to the group of death from respiratory diseases without silicosis $(n=57)^{20}$ or in the Eldorado uranium miner cohort with respect to death from total respiratory diseases $(n=158) .{ }^{21}$

The aim of the present analyses is to examine the quantitative relationship between occupational exposure to silica dust and radon progeny and mortality from non-malignant respiratory diseases (NMRD) with particular focus on COPD mortality in a large cohort of German uranium miners with individual data on exposure to respirable crystalline silica dust and radon. An increased risk of death from lung cancer due to radon ${ }^{22}$ and silica dust ${ }^{23}$ has already been demonstrated in this cohort. In a nested case-control approach among 1421 former German workers of the Wismut Company, a decline in the pulmonary function parameters and 
an increase in the incidence of COPDs in relation to silica dust have been reported by Möhner et al. ${ }^{24}$

\section{METHODS}

\section{Cohort design and follow-up}

The study population is based on a cohort of 58982 men employed at the former Wismut uranium mining company in East Germany, with at least 6 months of total employment between 1946 and $1989 .{ }^{25}$ Mortality follow-up period was from the date of first employment plus 180 days up to the first of either date of death, or emigration, or lost to follow-up, or 31 Dec 2008. Information on the vital status was obtained via local registration offices. Information on the underlying cause of death is based on certificates of deaths and autopsy files from the Wismut pathology archive and was coded according the International Classification of Diseases ICD-10. A total of 292 cohort members with missing information on silica dust exposure were excluded from the present analyses, leaving a total of 58690 cohort members for risk analysis. By the end of 2008 , 25250 men had died (43.0\%), 31306 (53.3\%) were alive, 534 $(0.9 \%)$ had emigrated and $1600(2.7 \%)$ were lost to follow-up. Information on cause of death was missing for $5.9 \%$ of the deceased.

\section{Retrospective assessment of exposure}

A comprehensive job-exposure matrix was used to retrospectively estimate the exposure to radon progeny in Working Level Months (WLM) for each of the following: (1) calendar year; (2) place of work (surface, underground, processing/milling, open pit); (3) mining facility/mine shaft; and (4) job type. ${ }^{26} 27$ WLM, a time-integrated measure, is the product of time in working months $(1$ month $=170 \mathrm{~h})$ and working levels. One working level is defined as any combination of radon progeny in $1 \mathrm{~L}$ of air that results in the ultimate emission of $130000 \mathrm{MeV}$ of energy from $\alpha$ particles. The radon progeny exposures were determined from either systematic measurements of radon taken since 1955 by the WISMUT company, or detailed expert ratings made prior to 1955. Data on the workhistory of all cohort members were extracted from the payrolls and personal files on a daily basis. On average, the radon progeny exposure levels were relatively high during the early years. However, levels reduced from about 1958 after the introduction of ventilation measures, reaching international radiation protection standards from $1970 .^{23}$

The job-exposure matrix (JEM) for respirable and inhalable fine dust and crystalline silica was similar to the radiation JEM. $^{27}{ }^{28}$ Here, systematic measurements in the shafts started in 1960. Dust concentrations before that time were retrospectively estimated by expert rating including reconstruction of historical workplaces and simulation of ventilation conditions. A detailed description of the measurements and the estimation methods is given elsewhere. ${ }^{28}$ Cumulative exposure to fine dust and respirable silica dust is given in $\mathrm{mg} / \mathrm{m}^{3}$-years where one dust-year equals an exposure of $1 \mathrm{mg} / \mathrm{m}^{3}$ over a full year with 220 shifts of $8 \mathrm{~h}$ each. Due to poor ventilation and dry drilling in the early years, the average shift silica dust concentrations were well above $2 \mathrm{mg} / \mathrm{m}^{3}$ specifically for underground workers and decreased continuously with increasing ventilation measures and the introduction of wet drilling (figure 1).

\section{Statistical methods}

Internal Poisson regression models were applied to examine possible exposure-response-relationships. Tabulations of personyears at risk and cancer deaths were created with the DATAB module of the EPICURE software. ${ }^{29}$ Cross-classifications were made by age, a, in 16 categories $(<15,15-19,20-24, \ldots, 85+$ years), individual calendar year, $y$, in 63 categories and cumulative radon exposure, $\mathrm{w}_{1}$, in 7 categories $(0,>0-10,10-49$, 50-199, 200-499, 500-999, 1000+WLM) or cumulative silica dust exposure, $\mathrm{w}_{2}$, in 7 categories $(0-0.5,0.5-2,2-5,5-10$, $10-20,20-30,30+\mathrm{mg} / \mathrm{m}^{3}$-years), respectively, as in previous publications. $^{22}$ A relative risk (RR) model, also called rate ratio model, was used of the following form:

$$
\mathrm{r}(\mathrm{a}, \mathrm{y}, \mathrm{w})=\mathrm{r}_{0}(\mathrm{a}, \mathrm{y}) \times\left\{1+\operatorname{ERR}\left(\mathrm{w}_{\mathrm{i}}\right)\right\}
$$

where $r$ is the cause-specific mortality rate, and $r_{0}$ is the baseline mortality rate (ie, without exposure). The covariables refer to age, a, and calendar year, y. Categorical analyses of the form excess relative risk (ERR) $(w)=\Sigma{ }_{j=1,7} \beta_{j} w_{i j}$ were performed,
Figure 1 Distribution of the average annual silica dust exposure in $\mathrm{mg} / \mathrm{m}^{3}$ for workers at five different work places (open pit, underground, surface, processing/milling and mixed).

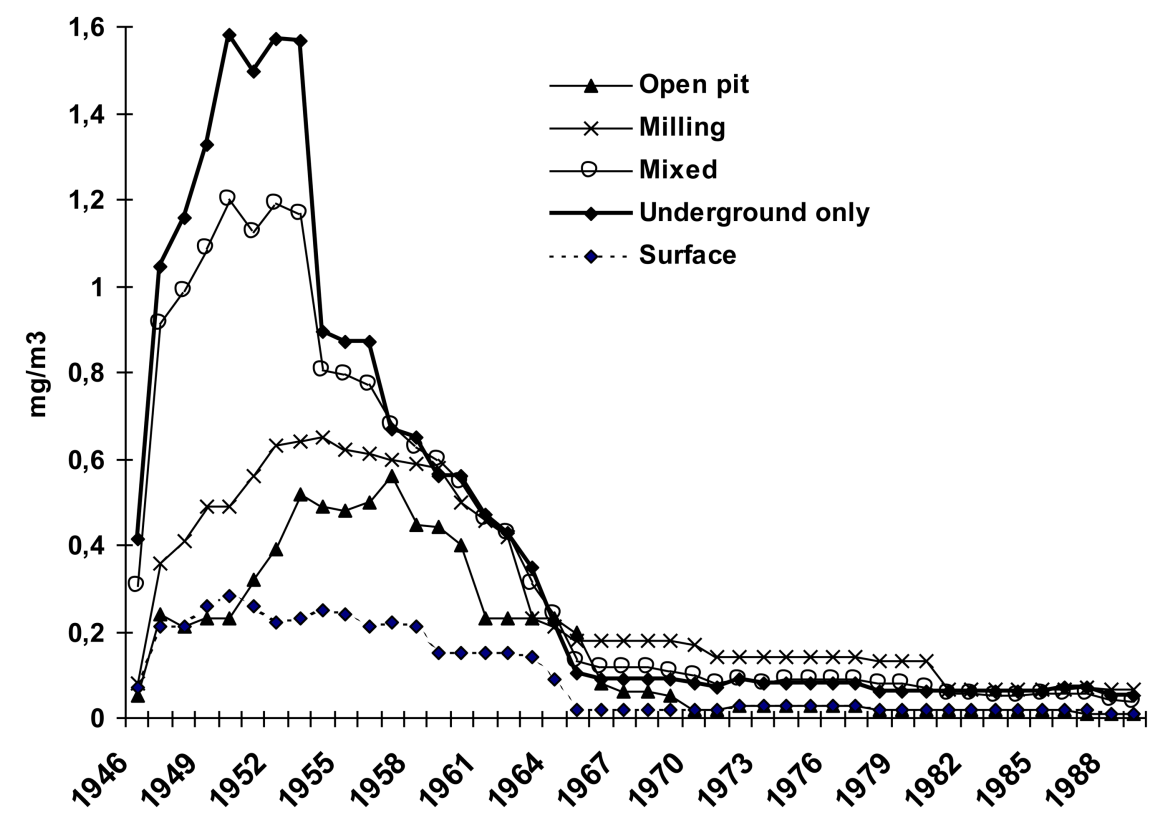


where $\mathrm{j}$ refers to the exposure class and $\mathrm{i}$ to exposure (radon or silica). The exposure-response relationship was estimated by means of a linear model of the form, $\operatorname{ERR}\left(\mathrm{w}_{\mathrm{i}}\right)=\beta \mathrm{w}_{\mathrm{i}}$, where $\left(\mathrm{w}_{\mathrm{i}}\right)$ or $\left(w_{j}\right)$ is the continuous variable of cumulative exposure to radon or silica, respectively. One exception was made for the subgroup of silicosis and other pneumoconiosis. In this group, RR-type models were affected by an undefined baseline rate (because silicosis without exposure is implausible), leading to unstable excess risk estimates. The exposure-response relationship was, therefore, modelled directly via an exponential linear quadratic model in exposure, adjusted for the age of the exposed cohort members, with parameters $\alpha_{1}, \alpha_{2}, \alpha_{3}, \beta, \gamma$ of the form

$$
\mathrm{r}(\mathrm{a}, \mathrm{w})=\exp \left(\alpha_{1}+\alpha_{2}(\mathrm{a}-50)+\alpha_{3}(\mathrm{a}-50)^{2}+\beta \mathrm{w}+\mathrm{gw}^{2}\right)
$$

where $\alpha_{2}, \alpha_{3}=0$, if $\mathrm{w}=0$ and $\alpha_{2}, \alpha_{3} \neq 0$, if $\mathrm{w}>0$.

In order to test for the potential confounder, silica, with respect to the radon-related ERR per WLM, or radon with respect to the silica-related ERR per $\mathrm{mg} / \mathrm{m}^{3}$-years, respectively, the respective variable $(\mathrm{z})$ was included in the RR model in a multiplicative way, $\operatorname{ERR}(\mathrm{w}, \mathrm{z})=\beta \mathrm{w}+\gamma \mathrm{z}+\theta \mathrm{wz}$ or additive way, $\operatorname{ERR}(\mathrm{w}, \mathrm{z})=\beta_{\mathrm{w}}+\gamma \mathrm{z}$. Because the multiplicative model provided a statistically significantly better fit, adjustment was performed in a multiplicative way. However, because results based on underlying cause of death were only marginally modified through adjustment, only the unadjusted results were presented. Findings indicated a healthy worker survivor effect, that is, a decrease in risk of NMRD with increasing cumulative silica exposure. Such a negative bias could occur when workers who are healthier and therefore have lower mortality rates, stay in employment longer and may accumulate higher exposures. To account for this type of bias, stratification by duration of employment in three categories $(<10,10-20,20+$ years $)$ was performed. This model led to statistically significant changes in the risk estimates compared to a model without stratification. Further stratification, for example, in 5-year bins, led to no substantial changes in the risk estimates, and was therefore not considered. All models were fitted with the AMFIT module of the EPICURE software ${ }^{29}$ with $95 \%$ Wald confidence limits. A lag time of 5 years was used to account for a latency period. Application of other lag times $(0,10,15)$ led to similar results and are therefore not given.

\section{RESULTS}

In the follow-up period from 1946 to 2008 with 2168455 person-years, a total of 2336 deaths (underlying cause) from NMRDs (J00-J99) were observed. Deaths from the subgroup of silicosis or other pneumoconiosis (J62, J64, J65) were predominant $(42 \%)$, followed by deaths from COPDs (J40-J44) (31\%). Table 1 shows the distribution of the underlying deaths from selected NMRDs by year of birth, year of first employment and year of death. The group of 715 deaths from COPDs (J40$\mathrm{J} 44$ ), included 103 deaths from chronic or non-specified bronchitis (J40-J42), 73 deaths from emphysema (J43), and 539 deaths from other chronic obstructive pulmonary disease (J44). The mean age at death from COPDs was 71 years, with a range of 42-95 years. Nearly all deaths from silicosis or other pneumoconiosis $(\mathrm{J} 62, \mathrm{~J} 64, \mathrm{~J} 65 ; \mathrm{n}=975)$ occurred in the group of miners with begin of employment at the Wismut Company before 1955, that is, the time with the highest silica exposures. The dominant subgroup was J62 $(n=757$; pneumoconiosis due to dust containing silica), followed by J65 ( $\mathrm{n}=213$, unspecified pneumoconiosis associated with tuberculosis), and J64 $(n=5$, unspecified pneumoconiosis excluding association with tuberculosis). The mean age at death from silicosis or other pneumoconiosis was 66 years (range: 32-93).

All cohort members were exposed at some time to silica dust, with appreciably lower levels for workers at the surface (figure 1). The mean (median) cumulative exposure was 5.9 (1.8) $\mathrm{mg} / \mathrm{m}^{3}$-years, the maximum $56 \mathrm{mg} / \mathrm{m}^{3}$-years. About $14 \%$ of the cohort members were never exposed to radon progeny. The mean (median) cumulative exposure to radon was 280 (33) WLM with a maximum of 3224 WLM among the exposed.

Table 2 shows the mortality from all NMRDs and the subgroups, pneumonia or influenza, COPD, and silicosis or other

Table 1 Cohort characteristics and distribution of deaths from non-malignant respiratory diseases in the Wismut cohort (1946-2008)

\begin{tabular}{|c|c|c|c|c|c|}
\hline & Number of workers & $\begin{array}{l}\text { Non-malignant respiratory } \\
\text { diseases } \\
(\mathrm{J} 00-\mathrm{J} 99)^{*}\end{array}$ & $\begin{array}{l}\text { Influenza and } \\
\text { pneumonia } \\
\text { (J00-J39) }\end{array}$ & $\begin{array}{l}\text { COPD } \\
\text { (J40-J44) }\end{array}$ & $\begin{array}{l}\text { Silicosis or othe } \\
\text { pneumoconiosis } \\
\text { (J62, J64-J65) }\end{array}$ \\
\hline Total & $58690(100)$ & $2336(100)$ & $477(100)$ & $715(100)$ & $975(100)$ \\
\hline \multicolumn{6}{|l|}{ Year of birth (\%) } \\
\hline 1900-1919 & $9236(15.7)$ & $990(42.4)$ & $213(45.6)$ & $321(44.8)$ & $400(41.0)$ \\
\hline 1920-1939 & 24980 (42.6) & $1264(54.2)$ & $231(47.1)$ & 370 (51.7) & $574(58.8)$ \\
\hline 1940-1959 & 16169 (27.6) & $75(3.2)$ & $30(6.1)$ & $24(3.4)$ & $1(0)$ \\
\hline 1960-1974 & $8306(14.2)$ & $6(0.3)$ & $2(0.4)$ & - & - \\
\hline \multicolumn{6}{|c|}{ Year of first employment (\%) } \\
\hline 1946-1955 & $23720(40.4)$ & $1927(82.5)$ & $343(71.5)$ & $528(73.8)$ & $939(96.2)$ \\
\hline 1956-1970 & 17868 (30.4) & 360 (15.5) & $130(24.3)$ & $174(24.3)$ & $35(0.4)$ \\
\hline 1971-1989 & $17102(29.1)$ & $48(2.1)$ & $18(3.5)$ & $13(1.8)$ & $1(0)$ \\
\hline \multicolumn{6}{|l|}{ Year of death (\%) } \\
\hline Before 1970 & $1634(2.8)$ & $135(5.8)$ & $11(1.3)$ & $20(2.8)$ & $100(10.3)$ \\
\hline 1970-1989 & 9084 (15.4) & $970(41.6)$ & $170(36.4)$ & $277(38.7)$ & $462(47.5)$ \\
\hline $1990-2008$ & $14532(24.8)$ & $1230(52.7)$ & $295(61.8)$ & 418 (58.5) & $413(42.2)$ \\
\hline Alive & $31306(53.3)$ & - & - & - & - \\
\hline Loss to follow-up & 2134 (3.6) & - & - & - & - \\
\hline
\end{tabular}


Table 2 Relative risk for selected subgroups of deaths from non-malignant respiratory diseases by cumulative silica exposure in the Wismut cohort (1946-2008)

\begin{tabular}{|c|c|c|c|c|c|c|c|c|c|c|c|}
\hline \multirow[b]{2}{*}{ (ICD-10 code) } & \multicolumn{11}{|c|}{ Cumulative silica exposure in $\mathrm{mg} / \mathrm{m}^{3}$-years } \\
\hline & & $0-0.5$ & $0.5-2$ & $2-5$ & $5-10$ & $10-20$ & $20-30$ & $30+$ & Total & $\begin{array}{l}\text { ERR/ } \\
\mathrm{mg} / \\
\mathrm{m}^{3} \text {-years }\end{array}$ & $\begin{array}{l}p \\
\text { Value }\end{array}$ \\
\hline All respiratory diseases ( J00-J99) & $\begin{array}{l}\text { Deaths } \\
\text { RR } \\
95 \% \mathrm{Cl}\end{array}$ & $\begin{array}{l}141 \\
1.00\end{array}$ & $\begin{array}{l}229 \\
0.95 \\
(0.75 ; 1.16)\end{array}$ & $\begin{array}{l}235 \\
0.85 \\
(0.66 ; 1.04)\end{array}$ & $\begin{array}{l}313 \\
1.01 \\
(0.79 ; 1.23)\end{array}$ & $\begin{array}{l}653 \\
1.78 \\
(1.41 ; 2.15)\end{array}$ & $\begin{array}{l}598 \\
3.73 \\
(2.94 ; 4.52)\end{array}$ & $\begin{array}{l}167 \\
5.05 \\
(3.77 ; 6.32)\end{array}$ & 2336 & 0.15 & $<0.001$ \\
\hline $\begin{array}{l}\text { Infectious diseases } \\
\text { and pneumonia } \\
\text { (J00-J39) }\end{array}$ & $\begin{array}{l}\text { Deaths } \\
\text { RR } \\
95 \% \mathrm{Cl}\end{array}$ & $\begin{array}{l}43 \\
1.00\end{array}$ & $\begin{array}{l}80 \\
1.16 \\
(0.71 ; 1.61)\end{array}$ & $\begin{array}{l}70 \\
0.92 \\
(0.54 ; 1.30)\end{array}$ & $\begin{array}{l}101 \\
1.09 \\
(0.65 ; 1.53)\end{array}$ & $\begin{array}{l}124 \\
1.16 \\
(0.69 ; 1.62)\end{array}$ & $\begin{array}{l}46 \\
0.96 \\
(0.51 ; 1.41)\end{array}$ & $\begin{array}{l}13 \\
1.25 \\
(0.42 ; 2.08)\end{array}$ & 477 & 0.004 & $>0.5$ \\
\hline $\begin{array}{l}\text { COPD } \\
(\mathrm{J} 40-\mathrm{J} 44)\end{array}$ & $\begin{array}{l}\text { Deaths } \\
\text { RR } \\
95 \% \mathrm{Cl}\end{array}$ & $\begin{array}{l}64 \\
1.00\end{array}$ & $\begin{array}{l}114 \\
0.98 \\
(0.67 ; 1.29)\end{array}$ & $\begin{array}{l}113 \\
0.81 \\
(0.55 ; 1.08)\end{array}$ & $\begin{array}{l}132 \\
0.85 \\
(0.57 ; 1.12)\end{array}$ & $\begin{array}{l}195 \\
1.07 \\
(0.74 ; 1.41)\end{array}$ & $\begin{array}{l}83 \\
1.07 \\
(0.68 ; 1.46)\end{array}$ & $\begin{array}{l}14 \\
0.87 \\
(0.34 ; 1.39)\end{array}$ & 715 & 0.007 & 0.24 \\
\hline $\begin{array}{l}\text { Silicosis or other } \\
\text { pneumoconiosis } \\
(\mathrm{J} 62, \mathrm{~J} 64, \mathrm{J65})\end{array}$ & $\begin{array}{l}\text { Deaths } \\
\text { RR } \\
95 \% \mathrm{Cl}\end{array}$ & & $\begin{array}{l}14 \\
1.00\end{array}$ & $\begin{array}{l}25 \\
2.19 \\
(0.74 ; 3.63)\end{array}$ & $\begin{array}{l}54 \\
4.15 \\
(1.64 ; 6.65)\end{array}$ & $\begin{array}{l}297 \\
17.56 \\
(8.39 ; 28.6)\end{array}$ & $\begin{array}{l}450 \\
60.55 \\
(27.8 ; 102.1)\end{array}$ & $\begin{array}{l}135 \\
88.88 \\
(39.3 ; 151.9)\end{array}$ & 975 & n.a. & n.a. \\
\hline Others & $\begin{array}{l}\text { Deaths } \\
\text { RR } \\
95 \% \mathrm{Cl}\end{array}$ & $\begin{array}{l}28 \\
1.00\end{array}$ & $\begin{array}{l}27 \\
0.61 \\
(0.26 ; 0.95)\end{array}$ & $\begin{array}{l}27 \\
0.56 \\
(0.23 ; 0.89)\end{array}$ & $\begin{array}{l}26 \\
0.54 \\
(0.21 ; 0.88)\end{array}$ & $\begin{array}{l}37 \\
0.66 \\
(0.28 ; 1.05)\end{array}$ & $\begin{array}{l}19 \\
0.86 \\
(0.27 ; 1.44)\end{array}$ & $\begin{array}{l}5 \\
1.20 \\
(<0 ; 2.44)\end{array}$ & 169 & 0.011 & 0.44 \\
\hline $\begin{array}{l}\text { Respiratory diseases without } \\
\text { silicosis /pneumoconiosis }\end{array}$ & $\begin{array}{l}\text { Deaths } \\
\text { RR } \\
95 \% \mathrm{Cl}\end{array}$ & $\begin{array}{l}135 \\
1.00\end{array}$ & $\begin{array}{l}222 \\
0.97 \\
(0.75 ; 1.19)\end{array}$ & $\begin{array}{l}210 \\
0.81 \\
(0.62 ; 0.99)\end{array}$ & $\begin{array}{l}259 \\
0.87 \\
(0.67 ; 1.08)\end{array}$ & $\begin{array}{l}354 \\
1.03 \\
(0.80 ; 1.27)\end{array}$ & $\begin{array}{l}148 \\
0.99 \\
(0.73 ; 1.26)\end{array}$ & $\begin{array}{l}32 \\
1.03 \\
(0.61 ; 1.45)\end{array}$ & 1361 & 0.006 & 0.14 \\
\hline Mean exposure & & 0.2 & 1 & 3 & 7 & 14 & 24 & 34 & 5.9 & & \\
\hline Person-years & & 753961 & 448223 & 299479 & 252454 & 277393 & 113018 & 23988 & 2168516 & & \\
\hline
\end{tabular}

pneumoconiosis in relation to cumulative silica dust exposure based on the underlying cause of death. In a first step, no adjustment for radon was performed. When all NMRDs were considered, there was a statistically significant increase in risk with increasing cumulative silica exposure. This increase, however, can be nearly completely attributed to the subgroup of deaths from silicosis or other pneumoconiosis. After excluding the latter group, there was no statistically significant excess of deaths (ERR per $\mathrm{mg} / \mathrm{m}^{3}$-years $=0.006,95 \%$ CI -0.002 to $0.015)$. By contrast with the subgroup of death from silicosis or other pneumoconiosis, the subgroups of deaths from COPDs, influenza or pneumonia and other NMRDs showed no trend in risk with silica. Even at very high concentrations of more than $30 \mathrm{mg} / \mathrm{m}^{3}$-years, no elevated RR was found. Additional adjustment for radon exposure did not alter the observed risks in all groups (data not shown). For example, the respective radon-adjusted ERR per $\mathrm{mg} / \mathrm{m}^{3}$-years for the group of all NMRDs, excluding silicosis or other pneumoconiosis, was 0.009 (95\% CI -0.004 to 0.022 ). In the group of deaths from silicosis or other pneumoconiosis, the first two exposure categories had to be collapsed for risk analyses, because of too few deaths in the reference category. There was a strong non-linear exposure-response relationship. Figure 2 shows the estimated relationship between mortality rates and cumulative silica dust exposure after application of an exponential linear quadratic model for ages 50,60 and 70 years.

The radon-related mortality risk was examined in the group of (underlying) deaths from NMRDs excluding silicosis or other pneumoconiosis, because the latter are solely occupational dust-related diseases (table 3). Overall, and in all considered subgroups of causes of death, no increase in mortality with increasing cumulative radon exposure was observed, even for high exposures above 1000 WLM. Risk estimates were not found to be modified after adjustment for silica dust exposure (data not shown). For example, when respiratory diseases without silicosis or other pneumoconiosis were considered, the ERR per 100 WLM was 0.005 (95\% CI -0.007 to 0.017 ), and -0.004 (95\% CI -0.020 to 0.011 ), without and with adjustment for silica exposure, respectively.

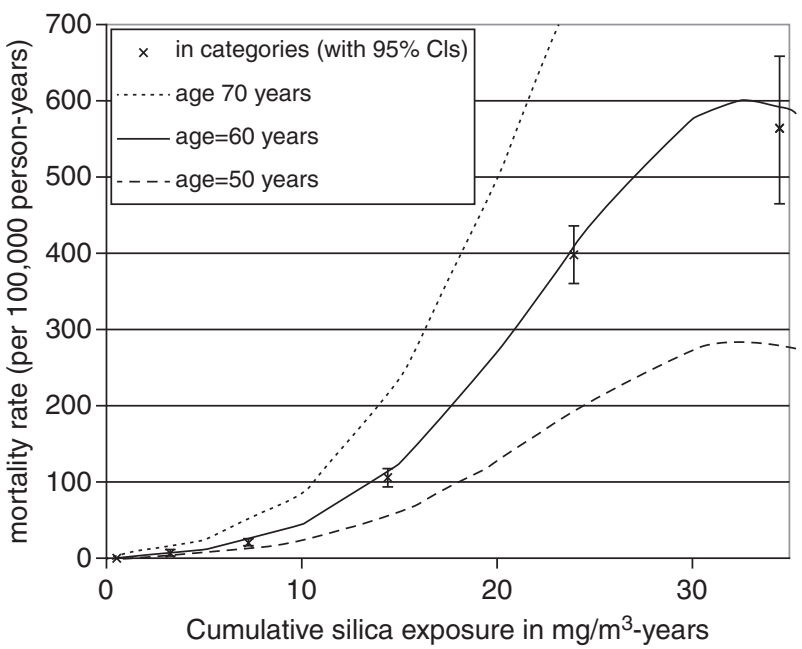

Figure 2 Mortality rates for the subgroup, silicosis and other pneumoconiosis $(n=975)$, in relation to cumulative silica dust in $\mathrm{mg} / \mathrm{m}^{3}$-years in the Wismut cohort, 1946-2008. The rates are shown in exposure categories (crosses, with error bars representing 95\% Cls) and from the model given in Equation 2. The model is shown as three lines for the exposure response for ages 50,60 and 70 years. The fit parameters, with $95 \% \mathrm{Cls}$, of the model given in Equation 2 (ie, $\mathrm{r}(\mathrm{a}, \mathrm{w})$ $\left.=\exp \left(\alpha_{1}+\alpha_{2}(a-50)+\alpha_{3}(a-50)^{2}+\beta w+\gamma w^{2}\right)\right)$ are: $\alpha_{1}=-11.16(-11.46$; $-10.86), \alpha_{2}=81.40$ (70.04; 92.76). 10 $0^{-3}, \alpha_{3}=-67.04(-104.4 ;-29.65)$. $10^{-5}, \beta=32.28$ (29.43; 35.12). $10^{-2}, \gamma=-49.14(-55.78 ;-42.50) .10^{-4}$. 
Table 3 Relative risk for selected subgroups of deaths from non-malignant respiratory diseases by cumulative radon exposure based on internal Poisson Regression in the Wismut cohort (1946-2008)

\begin{tabular}{|c|c|c|c|c|c|c|c|c|c|c|c|}
\hline \multirow[b]{2}{*}{ (ICD-10 code) } & \multicolumn{11}{|c|}{ Cumulative radon exposure in WLM } \\
\hline & & 0 & $>0-9$ & $10-49$ & 50-199 & $200-499$ & 500-999 & $1000+$ & Total & $\begin{array}{l}\text { ERR/100 } \\
\text { WLM }\end{array}$ & $\begin{array}{l}p \\
\text { Vvalue }\end{array}$ \\
\hline $\begin{array}{l}\text { All respiratory diseases without } \\
\text { silicosis or other pneumoconiosis } \\
\text { (not J62, J64, J65) }\end{array}$ & $\begin{array}{l}\text { Deaths } \\
\text { RR } \\
95 \% \mathrm{Cl}\end{array}$ & $\begin{array}{l}216 \\
1.00\end{array}$ & $\begin{array}{l}199 \\
1.04(0.84 \\
\text { to } 1.25)\end{array}$ & $\begin{array}{l}160 \\
1.08(0.85 \\
\text { to } 1.30)\end{array}$ & $\begin{array}{l}176 \\
1.06(0.84 \\
\text { to } 1.27)\end{array}$ & $\begin{array}{l}198 \\
1.03(0.83 \\
\text { to } 1.23)\end{array}$ & $\begin{array}{l}246 \\
1.16(0.95 \\
\text { to } 1.38)\end{array}$ & $\begin{array}{l}166 \\
1.12(0.88 \\
\text { to } 1.35)\end{array}$ & 1361 & 0.005 & 0.41 \\
\hline $\begin{array}{l}\text { Infectious diseases, pneumonia } \\
\text { (J00-J39) }\end{array}$ & $\begin{array}{l}\text { Deaths } \\
\text { RR } \\
95 \% \mathrm{Cl}\end{array}$ & $\begin{array}{l}72 \\
1.00\end{array}$ & $\begin{array}{l}81 \\
1.32 \\
(0.90 \text { to } \\
1.75)\end{array}$ & $\begin{array}{l}59 \\
1.21 \\
(0.79 \text { to } \\
1.64)\end{array}$ & $\begin{array}{l}59 \\
1.12 \\
(0.73 \text { to } \\
1.50)\end{array}$ & $\begin{array}{l}63 \\
1.02 \\
(0.67 \text { to } \\
1.37)\end{array}$ & $\begin{array}{l}82 \\
1.18 \\
(0.80 \text { to } \\
1.56)\end{array}$ & $\begin{array}{l}61 \\
1.20 \\
(0.77 \text { to } \\
1.62)\end{array}$ & 477 & -0.0002 & $>0.5$ \\
\hline $\begin{array}{l}\text { COPD } \\
(\mathrm{J} 40-\mathrm{J} 44)\end{array}$ & $\begin{array}{l}\text { Deaths } \\
\text { RR } \\
95 \% \mathrm{Cl}\end{array}$ & $\begin{array}{l}116 \\
1.00\end{array}$ & $\begin{array}{l}92 \\
0.91 \\
(0.66 \text { to } \\
1.16)\end{array}$ & $\begin{array}{l}77 \\
0.99 \\
(0.70 \text { to } \\
1.28)\end{array}$ & $\begin{array}{l}98 \\
1.07 \\
(0.78 \text { to } \\
1.36)\end{array}$ & $\begin{array}{l}110 \\
1.03 \\
(0.76 \text { to } \\
1.31)\end{array}$ & $\begin{array}{l}136 \\
1.17 \\
(0.88 \text { to } \\
1.47)\end{array}$ & $\begin{array}{l}86 \\
1.07 \\
(0.76 \text { to } \\
1.37)\end{array}$ & 715 & 0.007 & 0.41 \\
\hline Mean exposure & & 0 & 3.2 & 24 & 111 & 332 & 730 & 1443 & & & \\
\hline Person-years & & 530057 & 514486 & 320468 & 250666 & 209963 & 206187 & 136689 & 2168516 & & \\
\hline
\end{tabular}

Baseline stratified by age (5-year categories), calendar year (63 categories), duration of employment $(<10,10-20$ and $20+$ years).

COPD, chronic obstructive pulmonary disease; ERR, excess relative risk (linear model).

\section{DISCUSSION}

The present study showed no association between mortality from NMRDs excluding silicosis or other pneumoconiosis with either cumulative radon exposure or cumulative silica dust exposure, even at very high exposures. This was also true for the subgroup of deaths from COPDs or pneumonia. By contrast with this, a strong non-linear increase in mortality from silicosis or other pneumoconiosis with increasing cumulative silica dust levels was observed.

\section{Silicosis mortality and silica dust}

It is well established that silica exposure causes silicosis of variable severity. ${ }^{1}$ Mortality studies are rare, but show a consistent and strong increase in risk. ${ }^{7} 811$ 13-16 The currently largest study of 74040 Chinese workers at 29 metal mines and pottery factories included 2857 (underlying) deaths from pneumoconiosis (J60-J65). For a subset of workers who worked at annual respirable silica dust concentrations at or below $0.1 \mathrm{mg} / \mathrm{m}^{3}$ during their lifetime work history, the standardised mortality ratio (SMR) for pneumoconiosis was 11.0 (95\% CI 7.7 to 15.0). Internal Cox regressions resulted in a HR of 4.3 (95\% CI 3.7 to 4.9 ) in the exposure categories of $1.2-4.5$ vs $<1.2 \mathrm{mg} /$ $\mathrm{m}^{3}$-years of cumulative silica dust exposure. Both results indicate that long-term exposure to levels of silica dust below $0.1 \mathrm{mg} / \mathrm{m}^{3}$ (eg, an exposure to $0.1 \mathrm{mg} / \mathrm{m}^{3}$ over 45 years, equates $4.5 \mathrm{mg} / \mathrm{m}^{3}$ dust-years), the former workplace exposure limit for silica dust set by the US Occupational Safety and Health Administration, increase the risk of death. This was also noted in a pooled analyses of 11 cohorts including 172 silicosis deaths ${ }^{15}$ and in Swedish iron ore miners. ${ }^{14}$ In the present analysis, a twofold statistically insignificantly higher risk was found in the exposure category of $2-5$ vs $<2 \mathrm{mg} / \mathrm{m}^{3}$-years $(\mathrm{RR}=1.96$; 95\% CI 0.7 to 3.3). Misclassification of silica exposure, particularly in this low exposure range is a potential problem, because it cannot be fully excluded that a few persons may have worked in a silica-exposed job outside the Wismut Company, as also noted by Hedlund. ${ }^{14}$

\section{COPD mortality and silica dust}

The evidence on COPD mortality in relation to silica dust is sparse and inconsistent. Some studies reported a positive trend with respect to mortality from all NMRDs, including, however, a high percentage of deaths from silicosis. ${ }^{7}{ }^{12}$ Among British coal workers ${ }^{8}$ there was a significant trend with COPD mortality ( $n=869$ underlying deaths) for respirable dust and silica dust, but after mutual adjustment, this trend remained statistically significant only for respirable dust. No trend was observed in workers in the Norwegian carbide industry ${ }^{10}$ and workers in the UK industrial silica sand industry, ${ }^{9}$ but both studies suffered from small numbers of COPD deaths. In a large US study ${ }^{11}$ using National Occupational Mortality Surveillance data, a statistically significant trend in four silica-exposure categories in relation to mortality from COPDs was found, but no individual silica data were available. Among the Vermont granite workers, the risk of mortality from NMRDs, excluding silicosis, pneumonia, asthma, bronchitis, emphysema increased significantly with increasing cumulative silica exposure. ${ }^{13}$ Overall, previous results on mortality from COPDs due to silica dust are inconclusive.

By contrast with this, there is clear evidence of increasing loss of lung function with increasing silica dust exposure. ${ }^{4-6}$ This was also noted in a nested case-control study among Wismut workers. Here, a statistically significant increase in the incidence of COPD stage I in terms of Global Initiative for Chronic Obstructive Lung Diseases criteria in relation to silica exposure was found. ${ }^{24}$ It was a subsample of 1421 long-term low silica exposed miners (average annual exposure: $0-0.37 \mathrm{mg} / \mathrm{m}^{3}$ ) of the Wismut cohort, for which data on spirometry from regular medical examinations have been successfully determined. A potential limitation of this study is the low age at end of follow-up (range: 18-36 years) and a high percentage of excluded workers for which no or only one medical record could be traced.

\section{COPD mortality and radon exposure}

Presently, a causal link of adverse respiratory effects through exposure to radon progeny is only established for lung cancer. In the American Cancer Society Cohort (CPS-II) study, an increase in risk of COPD mortality with increasing mean county-level of residential radon exposure (ERR per 100 $\mathrm{Bq} / \mathrm{m}^{3}=13 \% ; 95 \%$ CI $5 \%$ to $21 \%$ ) was reported for the first time. ${ }^{17}$ The study had no individual data on residential radon exposure, and may therefore involve misclassification bias. On the other hand, it is a large cohort with individual data on cause 
of death and smoking habits-the major potential confounderand among all considered causes of death only those for lung cancer and COPDs showed a statistically significant radonrelated relationship. ${ }^{17} 18 \quad 30$ Previous miner studies examining the quantitative relationship between radon exposure and mortality from NMRDs ${ }^{21}$ or NMRDs without silicosis ${ }^{20}$ do not indicate an association, but these studies are rare. Given the magnitude of the observed increase in risk of COPD mortality by Turner et $a l,{ }^{17}$ this increase should be observable in the Wismut cohort. However, although the radon concentrations were appreciably higher (by a factor of 10-100) in the Wismut cohort compared with the CPS-II study, no such trend was observed.

\section{Strengths and limitations}

The strengths of this study include the large cohort size, the long follow-up time (average 34 years), the large number of deaths and the detailed high-quality assessment of radon and silica exposure with a wide range of exposures. One of the major limitations is the use of mortality data, and here the validity of cause of death especially with respect to NMRDs. To investigate age-dependent misclassification of cause of death, date of end of follow-up was restricted to age 75 years in sensitivity analyses. Risk estimates were similar to those obtained without restriction on age for all subgroups of NMRD. A major age-related misclassification bias is thus unlikely.

Under-reporting of, for example, COPDs due to comorbidity cannot be excluded. ${ }^{31} 32$ For this reason, sensitivity analyses considered COPDs mentioned as contributing or underlying cause of death on the death certificate or autopsy file, increasing the number of COPD deaths from 715 to 2673 deaths (data not shown). Based on these analyses, a clear trend in mortality from COPDs with silica dust (ERR per $\mathrm{mg} / \mathrm{m}^{3}$-years $=0.024 ; 95 \% \mathrm{CI}$ 0.011 to 0.038 ; adjusted for radon) and radon exposure (ERR per $100 \mathrm{WLM}=0.043$; $95 \%$ CI 0.024 to 0.062 ; adjusted for silica dust) was observed. Among the contributing COPD deaths, however, silicosis and lung cancer were the underlying causes of death for 275 and 388 individuals, respectively. Silicosis is known to be associated with COPD (COPD was mentioned in $27 \%$ of the 975 underlying deaths from silicosis), and the proportion of silicosis deaths also increases extremely with increasing silica dust, and indirectly with radon exposure due to a relatively high correlation of both exposures $(\mathrm{R}=0.70)$. Lung cancer is also known to be associated with COPDs ${ }^{31}$ and radon exposure $^{22}$ or silica exposure. ${ }^{23}$ The observed associations of COPD mortality with silica and radon exposure are likely to be due to bias through confounding. In fact, when COPD deaths with silicosis or lung cancer as the underlying cause were excluded from the analysis, no significant associations with cumulative silica or radon exposure were observed $(n=2010$, ERR per $\mathrm{mg} / \mathrm{m}^{3}$-years $=0.006 ; 95 \%$ CI -0.004 to 0.016 and ERR per $100 \mathrm{WLM}=0.013$; 95\% CI -0.003 to 0.029 ), respectively.

Missing causes of death is another potential source of bias. Many of the certificates of death in the years before 1970 were destroyed before the start of the cohort study in 1998. Therefore, the percentage of missing causes of death in the cohort in these earlier years was higher $(<1970 ; 50 \%)$ compared to later $(\geq 1970 ; 5 \%)$. However, sensitivity analyses based on the restricted follow-up period 1970-2008, showed no differences in risk estimates indicating that this type of bias is small.

The present study provided evidence for a healthy worker survivor bias, leading to a decrease in risk of mortality from
NMRD with increasing silica exposure without adjustment for duration of employment. There were regular medical examinations for all Wismut workers, and it is likely that workers with respiratory problems may not have been allowed to continue working underground. These workers may have moved to work places at the surface or left the WISMUT Company, and may thus have accumulated less cumulative exposure. Stratification for duration of employment in three categories $(<10,10-20$, $20+$ years) led to statistically significant changes in the risk estimates compared to a model without stratification. More detailed stratification only marginally changed the risk estimates. When mortality from all respiratory diseases without silicosis or other pneumoconiosis was considered, a statistically significant decrease in risk in the exposure category $2-5 \mathrm{mg} / \mathrm{m}^{3}$-years was present even after adjustment for duration of employment. The reasons are unclear. It could involve misclassification of exposure or misclassification of cause of death.

Smoking is the most important risk factor for NMRDs, and it is therefore advisable to perform detailed adjustment for smoking in studies of other risk factors. Unfortunately, only very limited and incomplete data on smoking exist in the full cohort that could not be used. In a nested case-control study on lung cancer, $^{33}$ it was shown that most Wismut miners were smokers and adjustment for smoking only marginally reduced the radon-related lung cancer risk. Smoking was broadly categorised into non-smokers defined as lifetime non-smokers or ex-smokers since 20 years or smokers. The correlations between this smoking status with cumulative radon exposure ${ }^{33}$ or silica dust $^{23}$ categories were very low and weakly positive, indicating no major confounding or at least no negative confounding, that is, underestimation of risk. The corresponding proportions of 'smokers' in the categories of cumulative silica dust exposure 0 $0.5,0.5-2,2-5,5-10,10-20,30+$ were $67 \%, 80 \%, 64 \%$, $72 \%, 70 \%, 80 \%, 78 \%$, among controls $(\mathrm{n}=400)$ and $92 \%$, 96\%, 98\%, 96\%, 94\%, 92\%, 96\% among lung cancer deaths $(n=600)$, respectively. Data on duration of smoking and intensity of smoking are missing in the nested case-control study. Thus, residual confounding cannot be excluded.

\section{CONCLUSION}

The present study confirms a strong relationship between silicosis mortality and cumulative silica dust exposure. By contrast with this, findings indicate no association between mortality from COPDs or other NMRDs and cumulative radon or silica dust exposure, even at high levels of exposure.

Acknowledgements We would like to thank Dr Annemarie Tschense from the BfS for medical advice and coordination of the mortality follow-up, and Dr Florian Dufey from the BfS for helpful discussions and statistical assistance.

Contributors All authors contributed to the conception and design and interpretation of the paper. Two authors, additionally, contributed to the statistical analyses (MS, LW); all authors drafted the article and revised it critically; all authors gave their final approval of the version to be published; MK is responsible for the overall content as guarantor.

\section{Competing interests None.}

Ethics approval The German Data Protection Agency.

Provenance and peer review Not commissioned; externally peer reviewed.

\section{REFERENCES}

1 NIOSH. National Institute for Occupational Safety and Health. Health effects of occupational exposure to respirable crystalline silica. DHHS (NIOSH) Publication No: 2002-129, 2002.

2 Viegi G, Pistelli F, Sherrill DL, et al. Definition, epidemiology and natural history of COPD. Eur Respir J 2007;30:993-1013.

3 Cullinan P. Occupation and chronic obstructive pulmonary disease (COPD). Br Med Bull 2012;104:143-61. 
4 Oxman $A D$, Muir DC, Shannon HS, et al. Occupational dust exposure and chronic obstructive pulmonary disease. A systematic overview of the evidence. Am Rev Respir Dis 1993:148:38-48.

5 Hnizdo E, Vallyathan V. Chronic obstructive pulmonary disease due to occupational exposure to silica dust: a review of epidemiological and pathological evidence. Occup Environ Med 2003;60:237-43.

6 Rushton L. Chronic obstructive pulmonary disease and occupational exposure to silica. Rev Environ Health 2007;22:255-72.

7 Chen W, Liu Y, Wang H, et al. Long-term exposure to silica dust and risk of total and cause-specific mortality in Chinese workers: a cohort study. PLoS Med 2012;9: e1001206.

8 Miller BG, MacCalman L. Cause-specific mortality in British coal workers and exposure to respirable dust and quartz. Occup Environ Med 2010;67:270-6.

9 Brown TP, Rushton L. Mortality in the UK industrial silica sand industry: 2. A retrospective cohort study. Occup Environ Med 2005;62:446-52.

10 Bugge MD, Foreland S, Kjaerheim K, et al. Mortality from non-malignant respiratory diseases among workers in the Norwegian silicon carbide industry: associations with dust exposure. Occup Environ Med 2011:68:863-9.

11 Calvert GM, Rice FL, Boiano JM, et al. Occupational silica exposure and risk of various diseases: an analysis using death certificates from 27 states of the United States. Occup Environ Med 2003:60:122-9.

12 Park R, Rice F, Stayner L, et al. Exposure to crystalline silica, silicosis, and lung disease other than cancer in diatomaceous earth industry workers: a quantitative risk assessment. Occup Environ Med 2002;59:36-43.

13 Vacek PM, Verma DK, Graham WG, et al. Mortality in Vermont granite workers and its association with silica exposure. Occup Environ Med 2011;68:312-18.

14 Hedlund $\mathrm{U}$, Jonsson $\mathrm{H}$, Erksson $\mathrm{K}$, et al. Exposure-response of silicosis mortality in Swedish iron ore miners. Ann Occup Hyg 2008;52:3-7.

15 't Mannetje A, Steenland K, Attfield M, et al. Exposure-response analysis and risk assessment for silica and silicosis mortality in a pooled analysis of six cohorts. Occup Environ Med 2002;59:723-8.

16 Steenland K. One agent, many diseases: exposure-response data and comparative risks of different outcomes following silica exposure. Am J Ind Med 2005:48:16-23.

17 Turner MC, Krewski D, Chen Y, et al. Radon and COPD mortality in the American Cancer Society Cohort. Eur Respir J 2012:39:1113-19.

18 Turner MC, Krewski D, Chen Y, et al. Radon and lung cancer in the American Cancer Society cohort. Cancer Epidemiol Biomarkers Prev 2011;20:438-48.
19 Schubauer-Berigan MK, Daniels RD, Pinkerton LE. Radon exposure and mortality among white and American Indian uranium miners: an update of the Colorado Plateau Cohort. Am J Epidemiol 2009:169:718-30.

20 Vacquier B, Caer S, Rogel A, et al. Mortality risk in the French cohort of uranium miners: extended follow-up 1946-1999. Occup Environ Med 2008:65:597-604.

21 Lane RSD, Frost SE, Howe GR, et al. Mortality (1950-1999) and cancer incidence (1969-1999) in the cohort of Eldorado uranium workers. Radiat Res 2010;174:773-85.

22 Walsh $L$, Tschense A, Schnelzer $M$, et al. The influence of radon exposures on lung cancer mortality in German uranium miners, 1946-2003. Radiat Res 2010;173:79-90.

23 Sogl M, Taeger D, Pallapies D, et al. Quantitative relationship between silica exposure and lung cancer mortality in German uranium miners, 1946-2003. Br J Cancer 2012;107:1188-94.

24 Möhner M, Kersten N, Gellissen J. Chronic obstructive pulmonary disease and longitudinal changes in pulmonary function due to occupational exposure to respirable quartz. Occup Environ Med 2013;70:9-14.

25 Kreuzer M, Schnelzer M, Tschense A, et al. Cohort profile: the German uranium miners cohort study (WISMUT cohort), 1946-2003. Int J Epidemiol 2010;39:980-7.

26 Lehmann F, Hambeck L, Linkert KH, et al. Belastung durch ionisierende Strahlung im Uranerzbergbau der ehemaligen DDR. Sankt Augustin: Hauptverband der gewerblichen Berufsgenossenschaften, 1998.

27 HVBG, BBG. Belastung durch ionisierende Strahlung, Staub und Arsen im Uranerzbergbau der ehemaligen DDR (Version 08/2005). Gera: Bergbau BG (BBG)، St. Augustin: Hauptverband der gewerblichen Berufsgenossenschaften (HVBG), 2005 (CD-Rom)

28 Dahmann D, Bauer HD, Stoyke G. Retrospective exposure assessment for respirable and inhalable dust, crystalline silica and arsenic in the former German uranium mines of SAG/SDAG Wismut. Int Arch Occup Environ Health 2008;81:949-58.

29 Preston DL, Lubin JH, Pierce DA, et al. Epicure, release 2.10. Hirosoft: Seattle, 1998.

30 Turner MC, Krewski D, Chen C, et al. Radon and nonrespiratory mortality in the American Cancer Society Cohort. Am J Epidemiol 2012;176:808-14.

31 Sin DD, Anthonisen NR, Soriano JB, et al. Mortality in COPD. Role of comorbidities. Eur Resp J 2006;28:1245-57.

32 Jensen $\mathrm{HH}$, Godtfredsen NS, Lange $P$, et al. Potential misclassification of causes of death from COPD. Eur Respir J 2006;28:781-5.

33 Schnelzer M, Hammer GP, Kreuzer M, et al. Accounting for smoking in the radon-related lung cancer risk among German uranium miners: results of a nested case-control study. Health Phys 2010;98:20-8. 


\section{Silica dust, radon and death from} non-malignant respiratory diseases in German uranium miners

M Kreuzer, M Sogl, I Brüske, M Möhner, D Nowak, M Schnelzer and L Walsh

Occup Environ Med 2013 70: 869-875 originally published online October 14,2013

doi: 10.1136/oemed-2013-101582

Updated information and services can be found at:

http://oem.bmj.com/content/70/12/869

\section{These include:}

References This article cites 29 articles, 20 of which you can access for free at: http://oem.bmj.com/content/70/12/869\#BIBL

Email alerting Receive free email alerts when new articles cite this article. Sign up in the service box at the top right corner of the online article.

Topic Articles on similar topics can be found in the following collections Collections

Respiratory (184)

\section{Notes}

To request permissions go to:

http://group.bmj.com/group/rights-licensing/permissions

To order reprints go to:

http://journals.bmj.com/cgi/reprintform

To subscribe to BMJ go to:

http://group.bmj.com/subscribe/ 